\title{
In vitro synergistic antitumor efficacy of sequentially combined chemotherapy/icotinib in non-small cell lung cancer cell lines
}

\author{
MIN-CONG WANG ${ }^{1}$, XUAN LIANG ${ }^{1}$, ZHI-YAN LIU $^{1,2}$, JIE CUI $^{1,3}$, YING LIU $^{1}$, LI JING ${ }^{1}$, \\ LI-LI JIANG $^{1}$, JIE-QUN MA ${ }^{1}$, LI-LI HAN ${ }^{1}$, QIAN-QIAN GUO ${ }^{1}$, CHENG-CHENG YANG ${ }^{1}$, \\ $\mathrm{JING}_{\text {WANG }}{ }^{1}$, TAO WU ${ }^{1}$, KE-JUN NAN ${ }^{1}$ and $\mathrm{YU} \mathrm{YAO}^{1}$ \\ ${ }^{1}$ Department of Oncology, The First Affiliated Hospital, College of Medicine of Xi'an Jiaotong University; \\ ${ }^{2}$ Department of Oncology, Zhong Xin Hospital, Xi'an; ${ }^{3}$ Department of Oncology, \\ Yanan University Affiliated Hospital, Yan'an, Shaanxi, P.R. China
}

Received May 28, 2014; Accepted August 25, 2014

DOI: 10.3892/or.2014.3583

\begin{abstract}
The concurrent administration of chemotherapy and epidermal growth factor receptor-tyrosine kinase inhibitors (EGFR-TKIs) has previously produced a negative interaction and failed to confer a survival benefit to non-small cell lung cancer (NSCLC) patients compared with first-line cytotoxic chemotherapy. The present study aimed to investigate the optimal schedule of the combined treatment of cisplatin/paclitaxel and icotinib in NSCLC cell lines and clarify the underlying mechanisms. HCC827, H1975, H1299 and A549 human NSCLC cell lines with wild-type and mutant EGFR genes were used as in vitro models to define the differential effects of various schedules of cisplatin/paclitaxel with icotinib treatments on cell growth, proliferation, cell cycle distribution, apoptosis, and EGFR signaling pathway. Sequence-dependent antiproliferative effects differed among the four NSCLC cell lines, and were not associated with EGFR mutation, constitutive expression levels of EGFR or downstream signaling molecules. The antiproliferative effect of cisplatin plus paclitaxel followed by icotinib was superior to that of cisplatin or paclitaxel followed by icotinib in the HCC827, H1975, H1299 and A549 cell lines, and induced more cell apoptosis and G0/G1 phase arrest. Cisplatin and paclitaxel significantly increased the expression of EGFR phosphorylation in the HCC 827 cell line. However, only paclitaxel increased the expression of EGFR phosphorylation
\end{abstract}

Correspondence to: Professor Ke-Jun Nan or Professor Yu Yao, Department of Oncology, The First Affiliated Hospital, College of Medicine of Xi'an Jiaotong University, No. 277 Yanta West Road, Xi'an, Shaanxi 710061, P.R. China

E-mail: nankj@163.com

E-mail: 13572101611@163.com

Abbreviations: EGFR, epidermal growth factor receptor; EGFRTKIs, epidermal growth factor receptor tyrosine kinase inhibitors; NSCLC, non-small cell lung cancer

Key words: non-small cell lung cancer, chemotherapy, icotinib, sequentially combined, epidermal growth factor receptor in the H1975 cell line. Cisplatin/paclitaxel followed by icotinib influenced the expression of p-EGFR and p-AKT, although the expression of $\mathrm{p}-\mathrm{ERK} 1 / 2$ remained unchanged. The results suggest that the optimal schedule of the combined treatment of cisplatin/paclitaxel and icotinib differed among the NSCLC cell lines. The results also provide molecular evidence to support clinical treatment strategies for NSCLC patients.

\section{Introduction}

Lung cancer is one of the leading causes of cancer mortality in developed countries, and non-small cell lung cancer (NSCLC) accounts for $80-85 \%$ of lung cancer cases (1). The majority of NSCLC patients have locally advanced or distant metastatic disease at the time of presentation and thus cannot undergo surgery (2). Platinum-based doublet chemotherapy is the mainstay of treatment for advanced NSCLC (3). However, it has significant side-effects and a 5-year survival rate of only $20 \%$ (4). Previous findings suggest that the chemotherapeutic treatments of NSCLC have reached a therapeutic plateau $(5,6)$. Thus, exploring new effective integrated treatment methods to improve the tumor response rate and prolong the survival time of advanced NSCLC patients is important.

The epidermal growth factor receptor (EGFR) pathway has been shown to be an important target in NSCLC proliferation. The emergence of EGFR-tyrosine kinase inhibitors (EGFR-TKIs) offers new hope to patients with advanced NSCLC patients. In 2004, it was reported that tumors with EGFR-activating mutations had histological characteristics of adenocarcinoma, and were highly sensitive to EGFR-TKIs with a better prognosis as compared to the EGFR wild-type (7-9). The efficiency of EGFR-TKIs reached 70-80\% and the median survival time was 20-30 months $(10,11)$. EGFR-TKIs are superior to cisplatin plus paclitaxel as an initial treatment for patients with advanced NSCLC harboring an EGFR mutation (12). Two randomized studies (WJTOG3405 and NEJ) showed that patients with an EGFR mutation have a high tumor response rate and progression-free survival (PFS) than those with EGFR-TKIs $(13,14)$. EGFR-TKIs provide a new option to patients since they can prolong survival and significantly improve the quality of life (15). 
The combination of EGFR-TKIs with chemotherapy is not more beneficial than chemotherapy alone (INTACT-1 and INTACT-2, TRIBUTE and TALENT) (16-19). An antagonistic effect exists between EGFR-TKIs and chemotherapy drugs. The failure to achieve positive results may be due to not being able to select EGFR-sensitizing mutations and using inappropriate drug administration sequences, thereby leading to cell cycle-specific antagonism (20-24).

Icotinib, an oral EGFR-TKI, has shown antitumor activity and favorable toxicity in early phase clinical trials. To assess the safety and tolerability of icotinib, Zhao et al selected NSCLC patients after the failure of prior platinum-based chemotherapy (25). Their results showed that oral icotinib is generally well tolerated with manageable and reversible adverse events, and shows positive clinical antitumor activities in patients with advanced NSCLC (25). A randomized, double-blind phase 3 non-inferiority trial showed that icotinib is non-inferior to gefitinib in terms of PFS, suggesting that icotinib is a new treatment option for pretreated patients with advanced NSCLC (26).

In the present study, we used human EGFR wild-type and mutant NSCLC cell lines to define the differential effects of cisplatin, paclitaxel and icotinib in different schedules on cell growth proliferation, cell cycle distribution, apoptosis and signaling pathways. Specifically, we tested the effects of cisplatin plus paclitaxel combined with icotinib in different schedules.

\section{Materials and methods}

Drugs. Icotinib, kindly provided by the Beida Pharmaceutical Company (China), was dissolved in $20 \mathrm{mM}$ dimethyl sulfoxide (DMSO; Sigma, St. Louis, MO, USA) as stocking solution. Cisplatin and paclitaxel were purchased from Sigma, and respectively dissolved in $1 \mathrm{mM}$ DMSO as stocking solution. The drugs were diluted with culture medium before use.

Cell lines. HCC827, H1975, H1299 and A549 human NSCLC cell lines were obtained from the Chinese Academy of Sciences Institute of Life Sciences Cell Resource Center in Shanghai. The cell lines were grown in RPMI-1640 medium supplemented with $10 \%$ fetal bovine serum and $100 \mathrm{UI} / \mathrm{ml}$ penicillin-streptomycin at $37^{\circ} \mathrm{C}$ in a humidified atmosphere with $5 \% \mathrm{CO}_{2}$. Cells in the exponential growth phase were harvested using trypsin-EDTA.

Gene sequencing. Genomic DNA was extracted from the HCC827, H1975, H1299 and A549 cell lines. The primers of EGFR exons 19-21 were designed using the ABI Prism ${ }^{\mathrm{TM}}$ Primer Express software (Applied Biosystems, Foster City, CA, USA) and amplified polymerase chain reaction of genomic DNA. The samples of positive amplified bands were then sequenced.

Evaluation of antiproliferative effects. Cell viability was determined using the tetrazolium dye 3-(4,5-dimethylthiazol-2-yl)-2,5-diphenyltetrazolium bromide (MTT) assay. Cells were seeded at $\sim 5,000 /$ well in 96 -well plates. At $24 \mathrm{~h}$ after seeding, the cells were exposed to the drugs. To evaluate the single-agent treatment, the cells were exposed to icotinib, cisplatin or paclitaxel alone for $72 \mathrm{~h}$, and the half maximal inhibitory concentration $\left(\mathrm{IC}_{50}\right)$ was considered as the concentration resulting in $50 \%$ cell growth inhibition compared with the untreated control cells. To evaluate the antiproliferative effects of the combined treatment, the cells were treated with three different sequences: i) pretreated with cisplatin/paclitaxel for $24 \mathrm{~h}$ and washed once with phosphate-buffered saline (PBS), followed by icotinib for $48 \mathrm{~h}$; ii) pretreated with icotinib for $48 \mathrm{~h}$ and washed once, followed by cisplatin/paclitaxel for $24 \mathrm{~h}$; iii) treated concomitantly with cisplatin/paclitaxel and icotinib for $48 \mathrm{~h}$, and incubated in drug-free medium for $24 \mathrm{~h}$. At $72 \mathrm{~h}$ after drug treatment, the cells were washed once with PBS and incubated with medium containing MTT $(0.5 \mathrm{mg} / \mathrm{ml}$ in medium) for $4 \mathrm{~h}$ at $37^{\circ} \mathrm{C}$. The culture medium with MTT was removed, and formazan crystals were reabsorbed in $200 \mu \mathrm{l}$ of DMSO (Sigma). Cell viability was determined by measuring the absorbance at $570 \mathrm{~nm}$. Experiments were conducted on at least three separate occasions. Thus, we used 0.125-, 0.25-, $0.5-, 1-, 2$ - and 4-fold the $\mathrm{IC}_{50}$ dose in cisplatin/paclitaxel and icotinib combination doses were used to calculate the combination index $(\mathrm{CI})$ value. The $\mathrm{CI}$ was calculated using CompuSyn software (ComboSyn, Inc., Paramus, NJ, USA). The resulting CI was a quantitative measure of the degree of interaction between different drugs, with $\mathrm{CI}>1.0, \mathrm{CI}=1.0$ and $\mathrm{CI}<1.0$, indicating antagonistic, additive and synergistic effects, respectively.

Clonogenic survival assays. To investigate the effects of chemotherapy followed by icotinib on the NSCLC cell lines, a standard clonogenic assay was performed. The cells were seeded in triplicate in 6 -well plates $\left(5 \times 10^{2}\right.$ cells/plate) and treated with DMSO as the vehicle control. After exposure to cisplatin/paclitaxel at $\mathrm{IC}_{50}$ levels for $24 \mathrm{~h}$, the cells were washed and exposed to icotinib at $\mathrm{IC}_{50}$ levels for $48 \mathrm{~h}$. The cells were then washed and incubated in drug-free medium for 14 days. Colonies were stained with crystal violet and manually counted. All of $\geq 50$ cells were counted. The survival fraction (SF) was estimated based on the formula: $\mathrm{SF}=$ number of colonies formed/number of cells seeded x plating efficiency of the control group. All the experiments were performed in triplicate.

Analysis of cell cycle and apoptosis. Cells were seeded in 6 -well plates at a density of $1 \times 10^{5} /$ well. After $24 \mathrm{~h}$, the cells were treated with cisplatin/paclitaxel and icotinib sequentially at $\mathrm{IC}_{50}$ levels. To analyze the cell cycle, cells were trypsinized, washed two times with PBS and harvested by centrifugation after the treatments were completed. The cells were then fixed with $70 \%$ ice-cold ethanol for at least $1 \mathrm{~h}$, centrifuged, washed two times in cold PBS, stained with propidium iodide (PI) solution $(0.05 \mathrm{mg} / \mathrm{ml} \mathrm{PI}$ and $10 \mathrm{mg} / \mathrm{ml}$ RNase A) for $20 \mathrm{~min}$ at $37^{\circ} \mathrm{C}$ in the dark, and analyzed using a flow cytometer (FACSCalibur; Becton-Dickinson Biosciences, San Jose, CA, USA). To analyze cell apoptosis, adherent and non-adherent cells were harvested after the drug treatments, washed with cold PBS, stained with Annexin V-fluorescein isothiocyanate (FITC) and PI (Joincare Medicine Company, China) for $15 \mathrm{~min}$ at $37^{\circ} \mathrm{C}$ in the dark and analyzed using a flow cytometer (FACSCalibur). 
Table I. $\mathrm{IC}_{50}$ values for each drug were calculated by performing dose-response experiments with cisplatin, paclitaxel and icotinib.

\begin{tabular}{lrrr}
\hline Cell lines & Cisplatin & Paclitaxel & \multicolumn{1}{c}{ Icotinib } \\
\hline HCC827 & $4.9 \mu \mathrm{mol} / 1$ & $1.6 \mathrm{nmol} / 1$ & $290 \mathrm{nmol} / 1$ \\
H1975 & $11.0 \mu \mathrm{mol} / 1$ & $1.7 \mathrm{nmol} / 1$ & $8.8 \mu \mathrm{mol} / 1$ \\
H1299 & $7.8 \mu \mathrm{mol} / 1$ & $13.3 \mathrm{nmol} / 1$ & $25.9 \mu \mathrm{mol} / 1$ \\
A549 & $5.7 \mu \mathrm{mol} / 1$ & $2.3 \mathrm{nmol} / 1$ & $6.9 \mu \mathrm{mol} / 1$ \\
\hline
\end{tabular}

Western blot analysis. After the drug treatments, the cells were harvested in ice-cold PBS and lysed with RIPA cell lysis buffer containing a protease inhibitor cocktail. The protein concentration was determined using the BCA protein assay reagent (both from Wolsen Company, China). Each protein sample was resolved on sodium dodecyl sulfate polyacrylamide gels $(8 \%)$, transferred onto polyvinylidene difluoride membranes (Millipore Corporation, Billerica, MA, USA), blocked for $1 \mathrm{~h}$ at room temperature in 5\% non-fat milk, and incubated with the appropriate primary antibodies according to the manufacturer's instructions. The primary antibodies EGFR, p-EGFR, AKT, p-AKT, ERK1/2, p-ERK1/2 and $\beta$-actin were purchased from Cell Signaling Technology, Inc. (Danvers, MA, USA). The blots were then washed with TBST for 30-40 min, and incubated with the secondary antibody (Wolsen Company) at room temperature for $1 \mathrm{~h}$. Secondary antibodies were also purchased from Cell Signaling Technology, Inc. For the quantification of protein levels, films were scanned and analyzed using Labworks software.

Statistical analysis. Data are expressed as the means \pm standard deviation (SD) of at least three experiments. Statistically significant differences between groups were determined by the Student's t-test using SPSS 19.0 software. In each case, $\mathrm{p}<0.05$ was considered to indicate a statistically significant result.

\section{Results}

EGFR gene sequencing. The specific primers used were for amplifying the cDNA fragments of the EGFR tyrosine kinase domain. Fig. 1 shows that the HCC827 cell line harbors the exon 19 sequence deletion. The H1975 cell line harbors the exon 20 sequence T790M mutation and exon 21 sequence L858R mutation. The H1299 and A549 cell lines were wild-types of EGFR.

Drug sensitivities of the HCC827, H1975, H1299 and A549 cell lines. Treatment with cisplatin, paclitaxel or icotinib alone for $72 \mathrm{~h}$ resulted in the dose-dependent inhibition of NSCLC cell growth. Table I summarizes the $\mathrm{IC}_{50}$ values of the three drugs. The four cell lines showed sensitivities similar to cisplatin and paclitaxel. The HCC827 cell line was highly sensitive to icotinib, whereas the H1975, H1299 and A549 cell lines showed resistance to icotinib.

Constitutive expression levels of EGFR and downstream signaling molecules in four NSCLC cell lines. We compared the basal EGFR expression levels of the NSCLC cell lines by western blotting. As shown in Fig. 2, the HCC827 cell line had significantly higher levels of EGFR and p-EGFR than A549, H1975 and H1299 cell lines. We also observed constitutive AKT and ERK1/2 phosphorylation in the four NSCLC cell lines. The basal AKT and p-AKT levels were similar in the four cell lines, although these levels were slightly lower in the HCC827 cell line. The ERK1/2 and p-ERK1/2 levels in the HCC827 cell line were higher than those in the other cell lines.

Sequence of cisplatin/paclitaxel followed by icotinib is more effective than other sequences in the NSCLC cell lines. To evaluate the antiproliferative effects of cisplatin, paclitaxel and icotinib treatments, we performed a series of MTT cell growth assays. We evaluated the antiproliferative effects on the HCC827, H1975, H1299 and A549 cell lines in three different sequences. Fig. 3A shows the schema for in vitro sequentially combined cisplatin/paclitaxel and icotinib treatments. As shown in Fig. 3B, the antiproliferative effects between cisplatin/paclitaxel and icotinib were sequence-dependent. Although the differences were not significant, the sequence of cisplatin/paclitaxel followed by icotinib was better than other sequences in the HCC827, H1975, H1299 and A549 cell lines.

The combined effect of cisplatin/paclitaxel and icotinib was evaluated on the basis of the CI (Fig. 4). In the HCC 827 cell line, which was highly sensitive to EGFR-TKIs, the sequence of cisplatin followed by icotinib resulted in a synergistic antiproliferative effect $(\mathrm{CI}<1)$. By contrast, the sequence of icotinib followed by cisplatin resulted in an antagonistic interaction $(C I>1)$. However, three different sequences of combined paclitaxel and icotinib resulted in an antagonistic and synergistic interaction with the increasing drug concentration. In the H1975 cell line harboring the T790M and L858R mutations of EGFR, the sequence of cisplatin followed by icotinib and concomitant administration resulted in a synergistic effect $(\mathrm{CI}<1)$, whereas the sequence of icotinib followed by cisplatin resulted in an antagonistic interaction $(\mathrm{CI}>1)$. Three different sequences of combined paclitaxel and icotinib resulted in antagonistic and synergistic interactions with the increasing drug concentration. The H1299 and A549 cell lines were wild-types of EGFR. In the H1299 cell line, a synergistic antiproliferative effect was observed with the sequence of cisplatin followed by icotinib and concomitant administration $(\mathrm{CI}<1)$. The sequence of icotinib followed by cisplatin resulted in an antagonistic interaction $(\mathrm{CI}>1)$. However, all three different sequences of combined paclitaxel and icotinib resulted in an antagonistic interaction. In the A549 cell line, the three different sequences of combined cisplatin/paclitaxel and icotinib resulted in synergistic and antagonistic interactions with the increasing drug concentration.

Three-drug combination is better than two-drug combination in the HCC827, H1299 and A549 cell lines, but not in the H1975 cell line. The antiproliferative effects of cisplatin plus paclitaxel followed by icotinib were compared with those of cisplatin or paclitaxel followed by icotinib. We determined that the antiproliferative effects of cisplatin plus paclitaxel followed by icotinib were better than those of cisplatin or paclitaxel followed by icotinib in the HCC827, H1299 and A549 cell lines (Fig. 5A). We also evaluated the effects of 
A
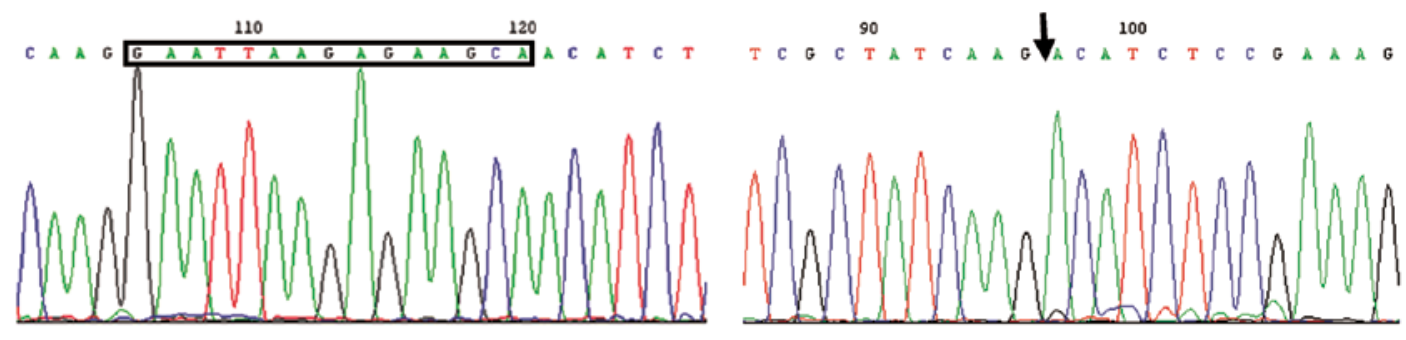

\section{B}
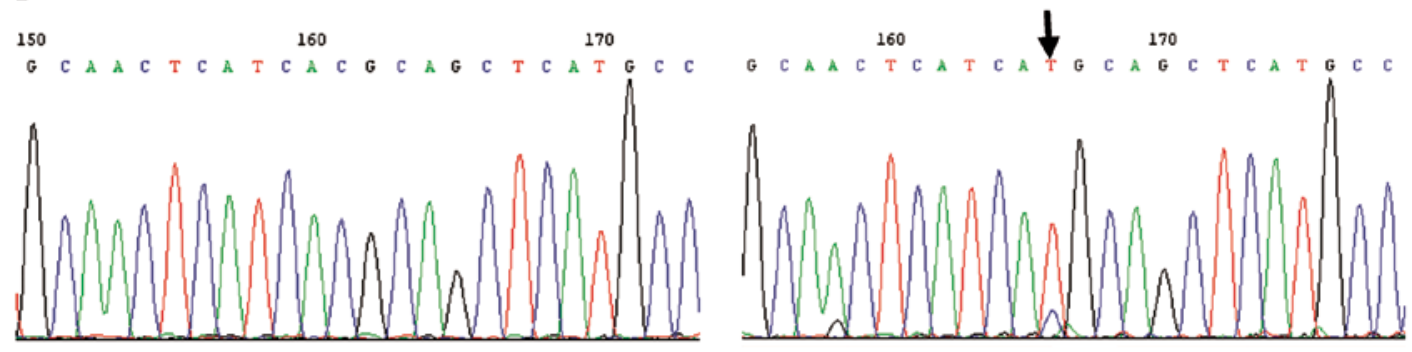

C
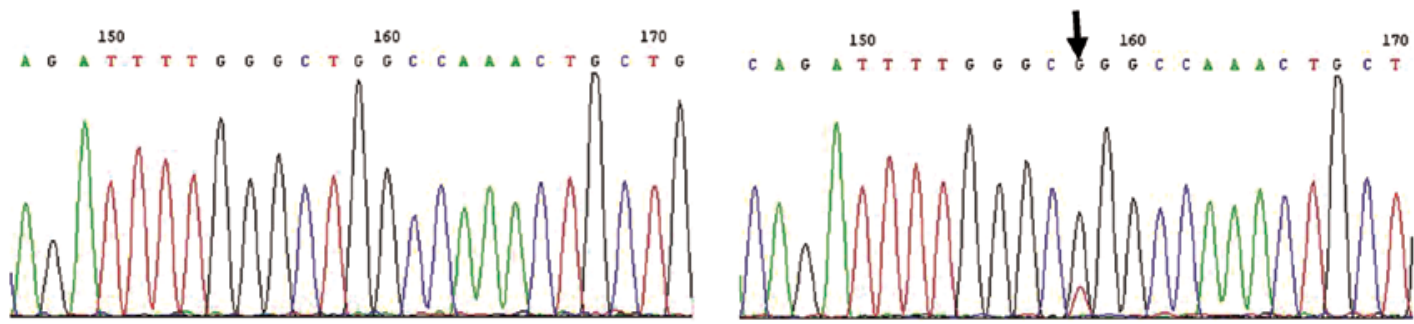

Figure 1. HCC827 and H1975 EGFR exon 19-21 sequences. (A) EGFR exon 19 wild-type and HCC827 EGFR exon 19 sequence deletion. (B) EGFR exon 20 wild-type and H1975 EGFR exon 20 sequence T790M mutation. (C) EGFR exon 21 wild-type and H1975 EGFR exon 21 sequence L858R mutation. EGFR, epidermal growth factor receptor.
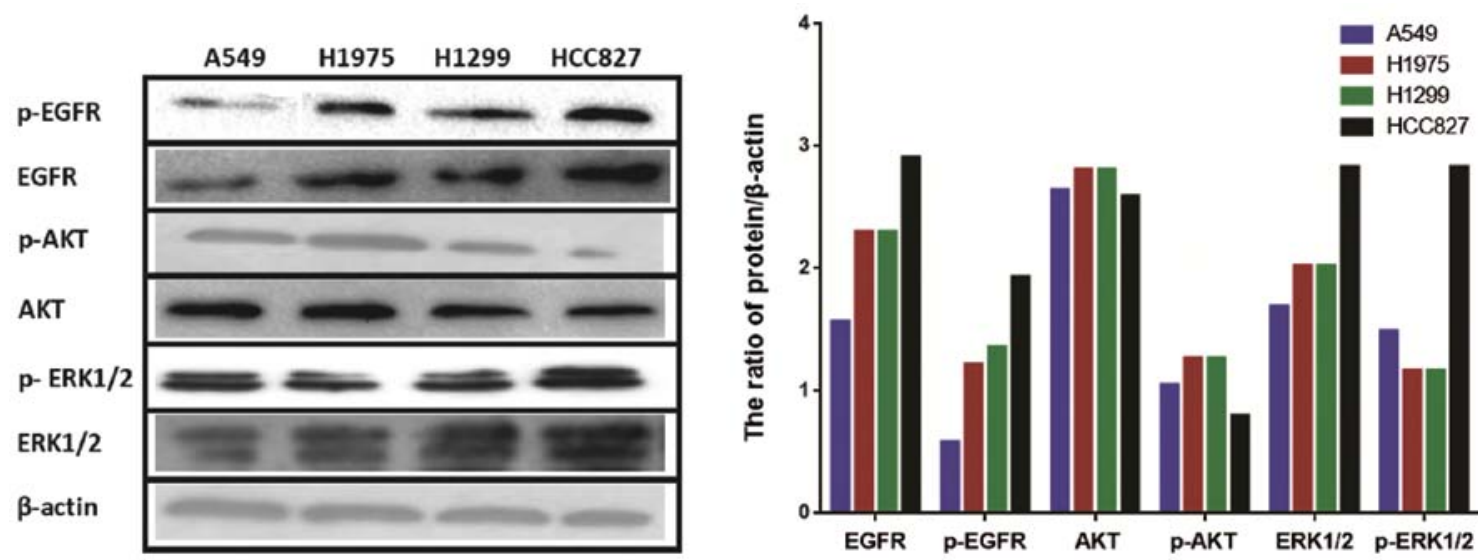

Figure 2. Constitutive expression of EGFR and the downstream signaling molecules in human NSCLC cell lines. EGFR, epidermal growth factor receptor; NSCLC, non-small cell lung cancer.

cisplatin plus paclitaxel followed by icotinib in the HCC827 and H1975 cell lines using a clonogenic assay (Fig. 5B and C). Cells were exposed to cisplatin, paclitaxel and icotinib at the $\mathrm{IC}_{50}$ values. The combinations, regardless of whether they were three-drug or two-drug, decreased the survival rates of HCC827 and H1975 cells compared with the control group. Clonogenic survival of cisplatin plus paclitaxel followed by icotinib was the lowest compared with that of cisplatin or pacli- taxel followed by icotinib in the HCC827 cell line (three-drug combination vs. two-drug combination, $\mathrm{p}<0.05)$, but not in the H1975 cell line ( $\mathrm{p}>0.05)$.

Three-drug combination induced more G0/G1 phase arrest and apoptosis than the two-drug combination in the HCC 827 cell line, but not in the H1975 cell line. DNA flow cytometry studies were performed to evaluate the effect of drug 
A

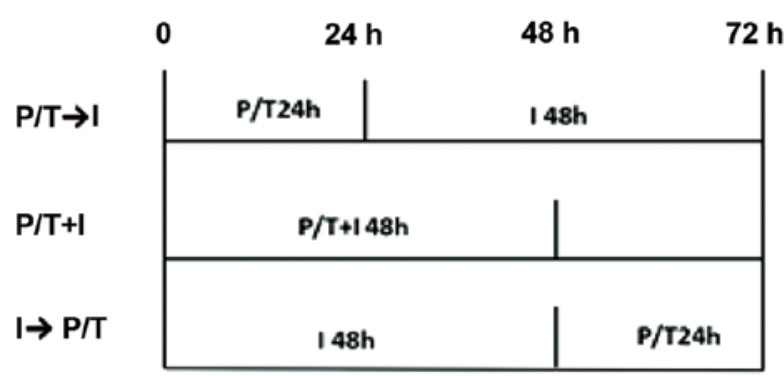

B

HCC827

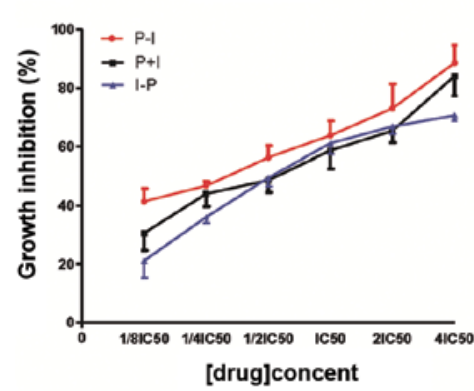

H1975

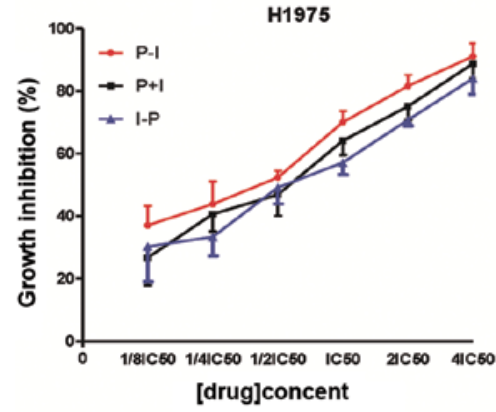

H1299

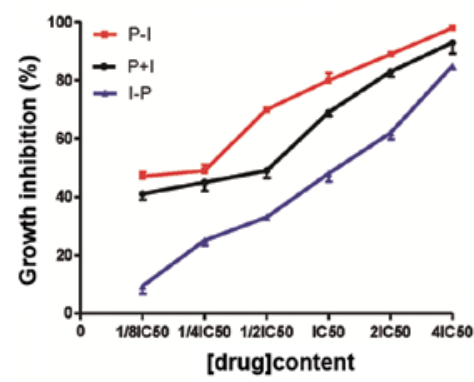

A549

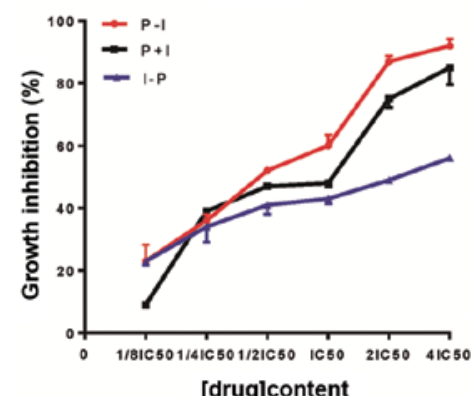

HCC827

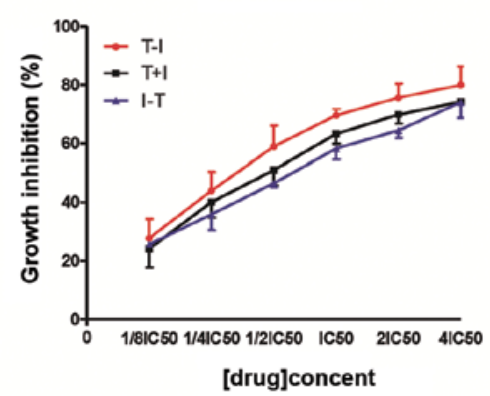

H1975

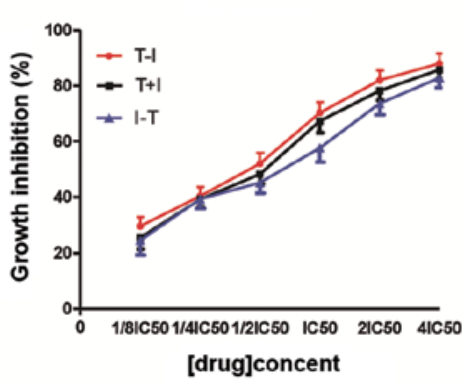

H1299

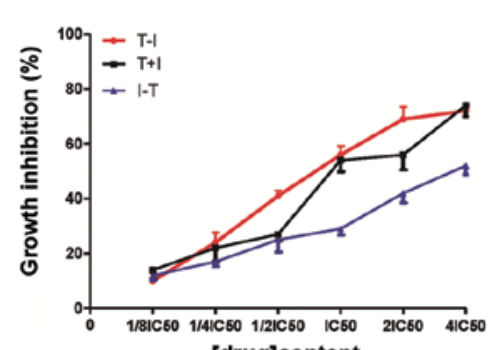

[drug]content

A549

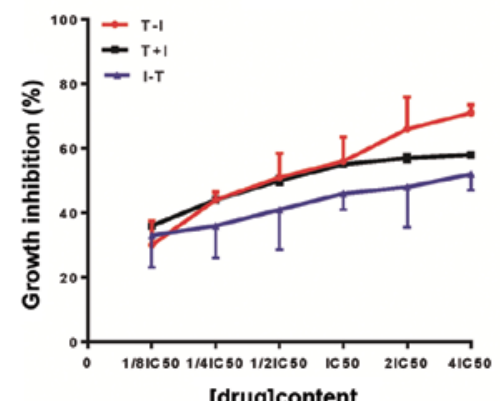

$72 \mathrm{~h}$$$
\text { (1) }
$$

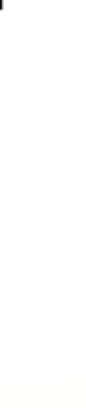


HCC 827

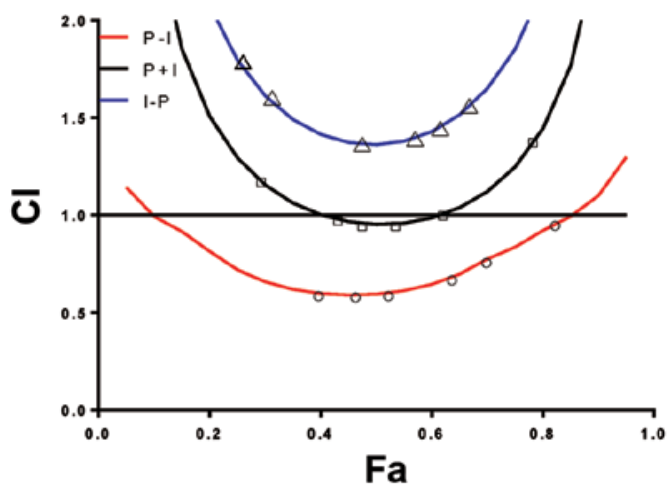

H1975

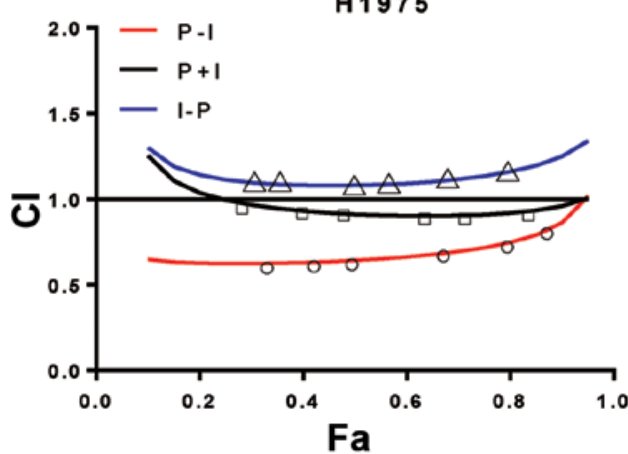

H1299

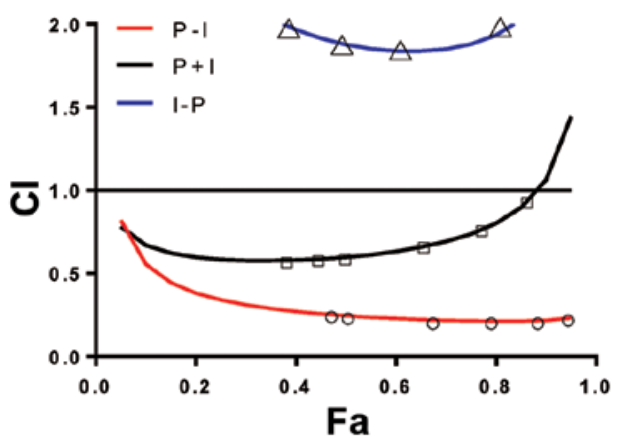

A 549

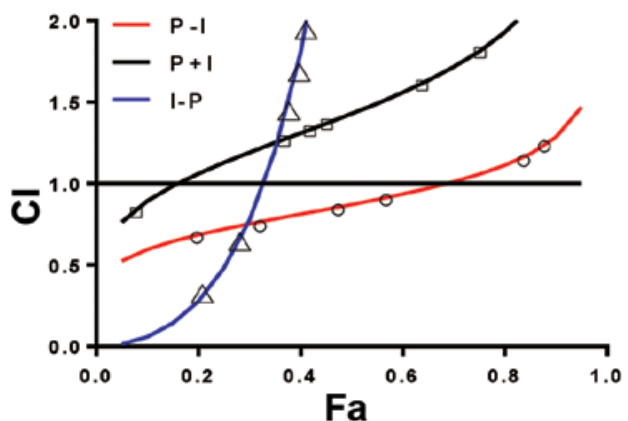

HCC 827

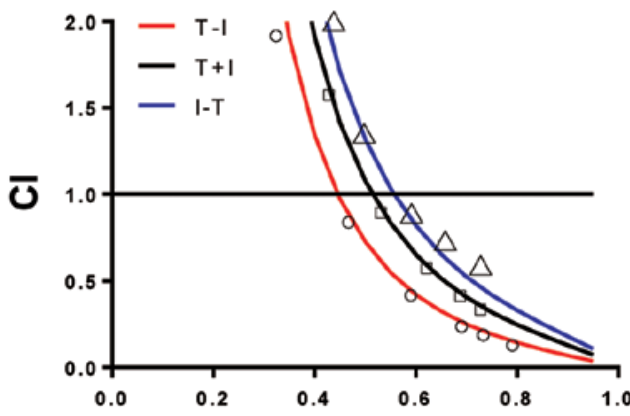

Fa

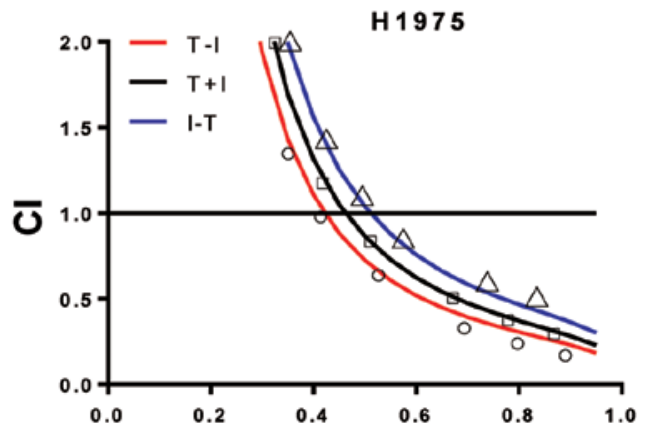

$\mathrm{Fa}$

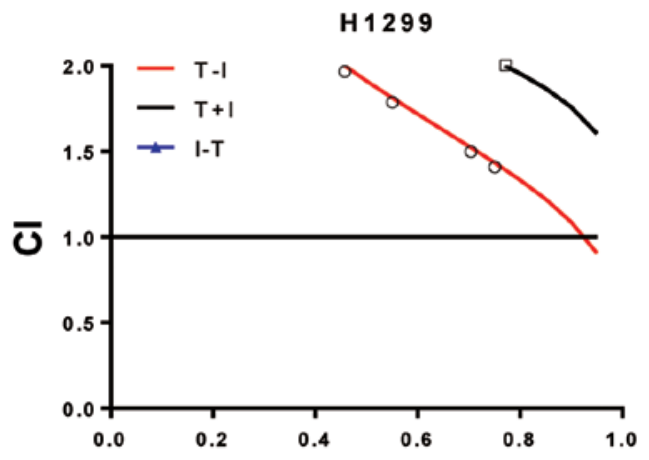

$\mathrm{Fa}$

\section{A 549}

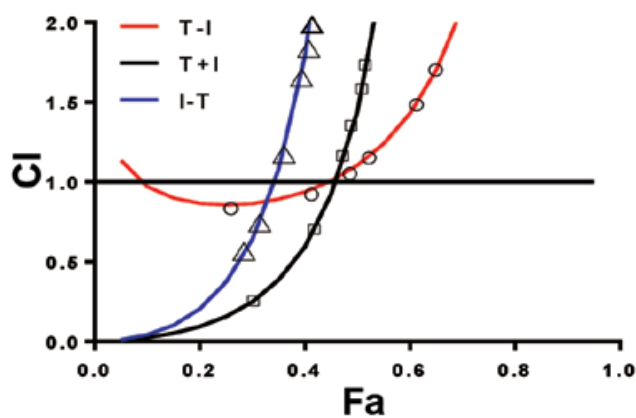

Figure 4. Synergism of sequence-dependent cytotoxicity between cisplatin/paclitaxel and icotinib in the NSCLC cell lines. The P-I sequence resulted in a synergistic effect in the HCC827, H1975 and H1299 cell lines. The T-I sequence resulted in a synergistic effect in the HCC827 and H1975 cell lines in high drug concentrations. By contrast, the P-I and T-I sequences resulted in a synergistic effect in low drug concentrations in the A549 cell line. CI, combination index; Fa, fraction cell-growth inhibition; NSCLC, non-small cell lung cancer.

combinations on the cell cycle distribution. We selected the HCC827 and H1975 cell lines to determine whether their cell cycle-modulating activity provides evidence clues to optimize drug scheduling. The cells were exposed to cisplatin, paclitaxel and icotinib at the $\mathrm{IC}_{50}$ values. All the agents affected the cell cycle of the HCC827 and H1975 cell lines (Fig. 6A). 
A

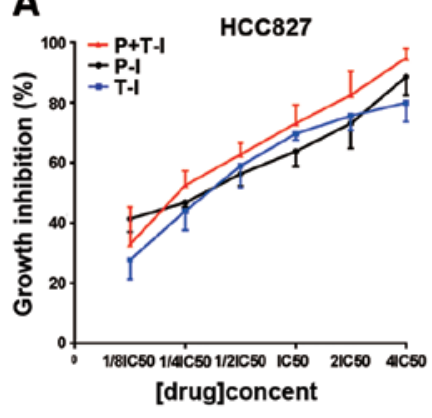

HCC827

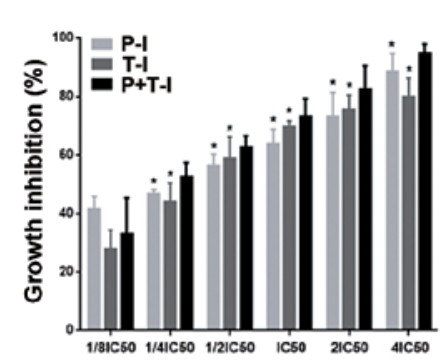

B

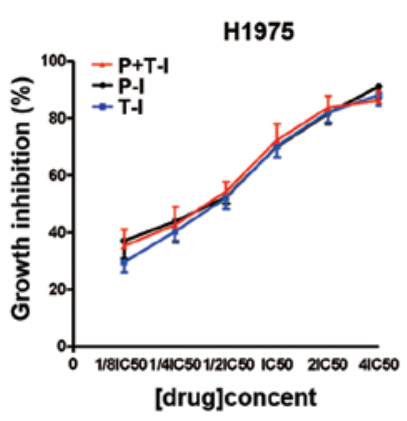

H1975

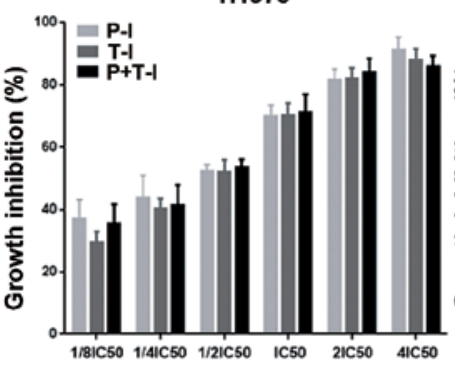

H1299

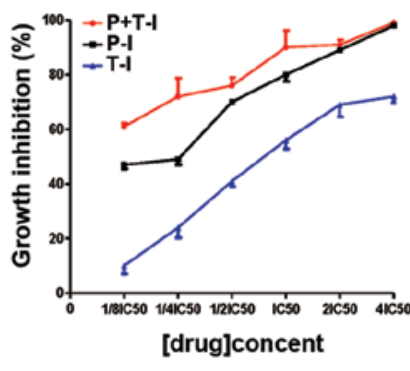

H1299

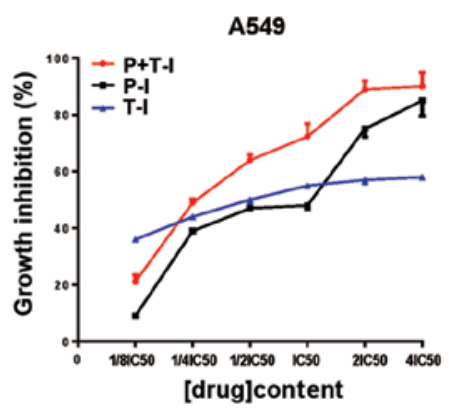

A549
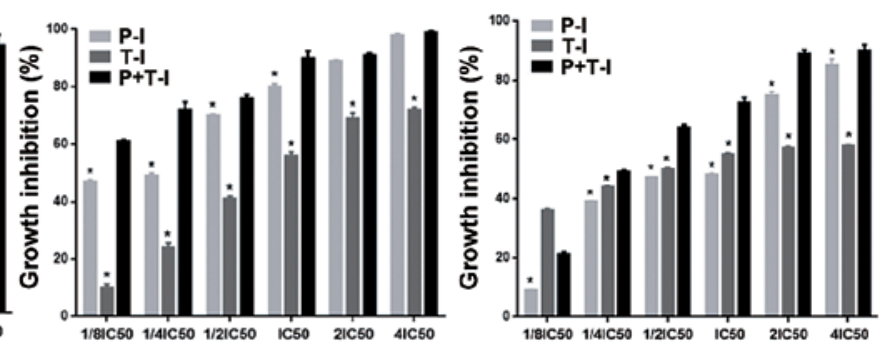

C
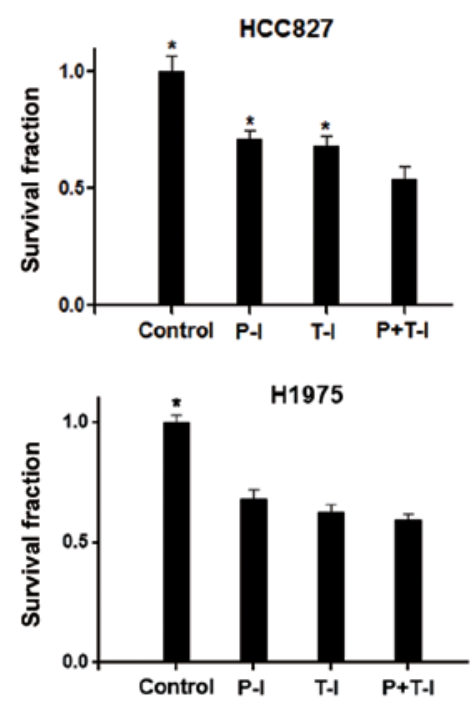

Figure 5. Antiproliferative effects of the three-drug combination are better than those of the two-drug combination in the HCC827, H1299 and A549 cell lines. (A) The antiproliferative effects of cisplatin plus paclitaxel followed by icotinib were better than those of cisplatin or paclitaxel followed by icotinib in the HCC827, H1299 and A549 cell lines. (B and C) Clonogenic assay was performed in the HCC827 and H1975 cell lines. Colonies were counted 14 days later. Data are presented as the means \pm SD from three independent experiments and shown in bar graphs $\left({ }^{*} \mathrm{p}<0.05 \mathrm{vs}\right.$. $\left.\mathrm{P}+\mathrm{T}-\mathrm{I}\right)$.

In response to the treatment of cisplatin followed by icotinib, cell fractions in the $\mathrm{S}$ phase decreased $(26 \pm 2.0$ and $15 \pm 1.8 \%)$ whereas those in the G0/G1 phase increased $(63 \pm 1.4$ and $69 \pm 1.8 \%$ ) compared with the control group in the HCC 827 and $\mathrm{H} 1975$ cell lines, respectively. In response to the treatment of paclitaxel followed by icotinib, cell fractions in the $S$ phase also decreased $(21 \pm 1.5$ and $14 \pm 1.3 \%)$, whereas those in the G0/G1 phase increased $(64 \pm 1.9$ and $71 \pm 2.0 \%)$. After the treatment with cisplatin plus paclitaxel followed by icotinib, the proportion of the HCC 827 cell line in the G0/G1 phase significantly increased compared with that in the other treatment groups $(72 \pm 0.8 \%, \mathrm{p}<0.05)$. However, no difference was observed in the H1975 cell line $(71 \pm 1.7 \%, \mathrm{p}>0.05)$.

Double staining with Annexin V-FITC and PI was used to determine whether growth inhibition was due to the induction of apoptosis. Cells were exposed to cisplatin, paclitaxel and icotinib at the $\mathrm{IC}_{50}$ values. As shown in Fig. $6 \mathrm{~B}$, the proportions of apoptotic cells in the HCC827 and H1975 cell lines induced by cisplatin followed by icotinib were $31.6 \pm 0.4$ and $16.4 \pm 1.6 \%$, respectively. The proportions of apoptotic cells in the HCC827 and $\mathrm{H} 1975$ cell lines induced by paclitaxel followed by icotinib were $35.2 \pm 1.0$ and $18.0 \pm 2.0 \%$, respectively. The proportion of apoptotic cells in the HCC827 cell line treated with cisplatin plus paclitaxel followed by icotinib was higher than that in the HCC827 cell line treated with cisplatin or paclitaxel followed by icotinib $(39.4 \pm 0.3 \%, \mathrm{p}<0.05)$. However, no difference was observed in the H1975 cell line $(21.0 \pm 3.8 \%, \mathrm{p}>0.05)$.

Effect of cisplatin, paclitaxel and icotinib on EGFR and downstream signaling molecules in the HCC827 and H1975 
A

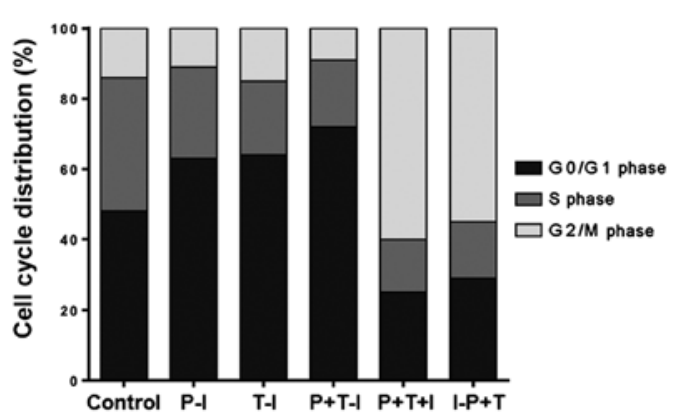

HCC827

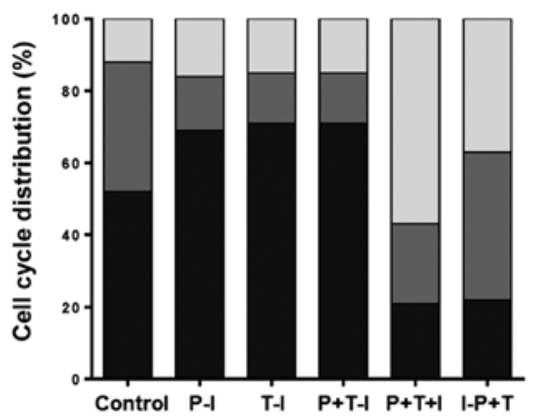

B

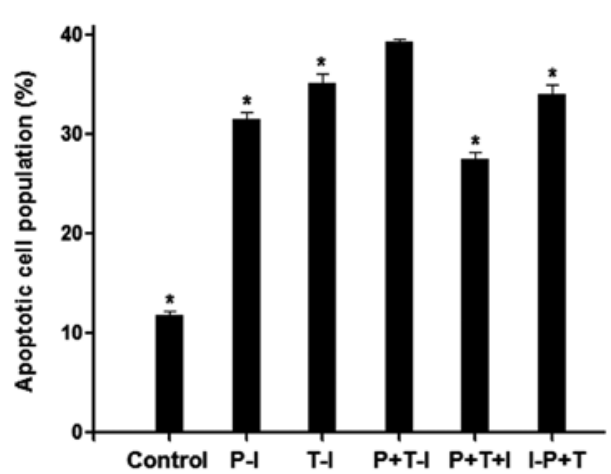

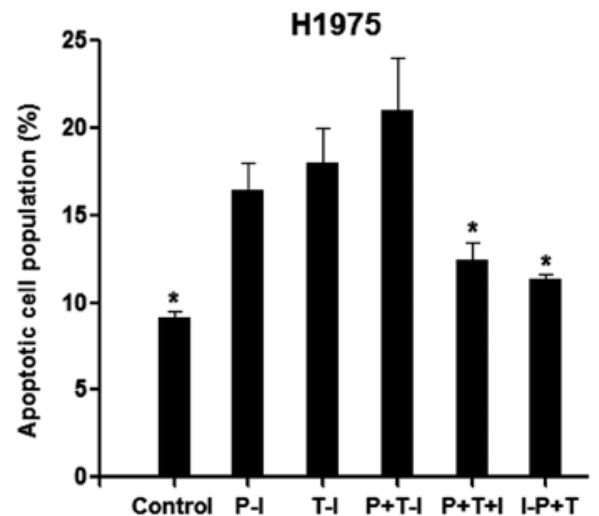

Figure 6. Effects of cisplatin, paclitaxel and icotinib in combination on the cell cycle distribution and apoptosis. (A) Cell cycle distribution was analyzed by flow cytometry. Data are presented as the mean value. (B) Apoptotic (Annexin $\mathrm{V}^{+}$) and necrotic (Annexin $\mathrm{V}^{-} / \mathrm{PI}^{+}$) cells were counted by flow cytometry. Cells were treated with the $\mathrm{IC}_{50}$ value of drugs. Data are presented as the means \pm SD from three independent experiments. Statistically significant differences between P+T-I and other treatment groups are presented as " $\mathrm{p}<0.05$.

cell lines. To gain insight into the mechanisms involved in regulating the interaction of cisplatin, paclitaxel and icotinib, we examined the effects on EGFR and downstream signaling molecules in the HCC827 and H1975 cell lines (Fig. 7). The cells were exposed to the $\mathrm{IC}_{50}$ doses of drugs. Exposure to cisplatin, paclitaxel or icotinib alone resulted in no changes in the total proteins of EGFR, AKT and ERK1/2 in the HCC827 and H1975 cell lines. The HCC827 cell line exhibited increases in p-EGFR and p-AKT in response to cisplatin alone, although p-ERK1/2 was unchanged. When the HCC827 cell line was exposed to paclitaxel alone, the p-EGFR levels significantly increased, whereas the p-AKT and p-ERK1/2 levels were unchanged. We observed that icotinib significantly inhibited p-EGFR, p-AKT and p-ERK1/2 in the HCC827 cell line (Fig. 7A). In the H1975 cell line, we observed an increase in the p-AKT level after cisplatin. In addition, the paclitaxel-treated H1975 cell line showed an increase in the p-EGFR and p-AKT levels. Icotinib-treated H1975 cells showed a decrease in the p-EGFR and p-AKT levels, although the p-ERK1/2 level was unchanged (Fig. 7B).

We also examined the effect of cisplatin/paclitaxel followed by icotinib on EGFR and downstream signaling molecules in the HCC827 and H1975 cell lines (Fig. 7C). In the HCC827 and $\mathrm{H} 1975$ cell lines, the combinations of cisplatin/paclitaxel followed by icotinib affected the expression of $\mathrm{p}-\mathrm{EGFR}$ and p-AKT, but not p-ERK1/2. In the HCC827 cell line, the expression levels of $\mathrm{p}-\mathrm{EGFR}$ and $\mathrm{p}-\mathrm{AKT}$ with cisplatin plus paclitaxel followed by icotinib were significantly lower than those of cisplatin or paclitaxel followed by icotinib $(\mathrm{p}<0.05)$, although not in the H1975 cell line.

\section{Discussion}

The present study aimed to investigate the optimal schedule of combined treatment with cisplatin/paclitaxel and icotinib in NSCLC cell lines, and gain insight into the molecular mechanisms underlying the interaction of these drugs in vitro. In the present study, we observed that the sequence of cisplatin followed by icotinib resulted in a synergistic effect on the HCC827, H1975 and H1299 cell lines. In addition, paclitaxel followed by icotinib showed a synergistic effect in the HCC827 and H1975 cell lines at high concentrations. However, the sequences of cisplatin followed by icotinib and paclitaxel followed by icotinib resulted in synergistic effects only in low concentrations in the A549 cell line. The antiproliferative effect of cisplatin plus paclitaxel followed by icotinib was superior to that of cisplatin or paclitaxel followed by icotinib in the HCC827, H1299 and A549 cell lines, although not in the H1975 cell line harboring the T790M and L858R mutations. This antiproliferative effect seemed to have no correlation with the constitutive expression levels of EGFR and downstream signaling molecules in the four NSCLC cell lines. We also determined that the potentiation of the antiproliferative activity of EGFR-TKI and chemotherapy in combination was sequence-dependent.

In previous studies sequence-dependent interactions between EGFR-TKIs and chemotherapy in human cancer cell lines were shown (27). Cheng et al observed that the sequence of paclitaxel followed by gefitinib is an appropriate treatment combination that is superior to other sequences in treating 
A

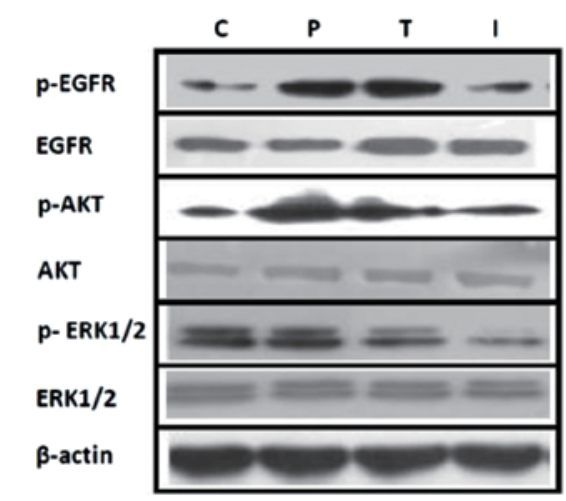

B

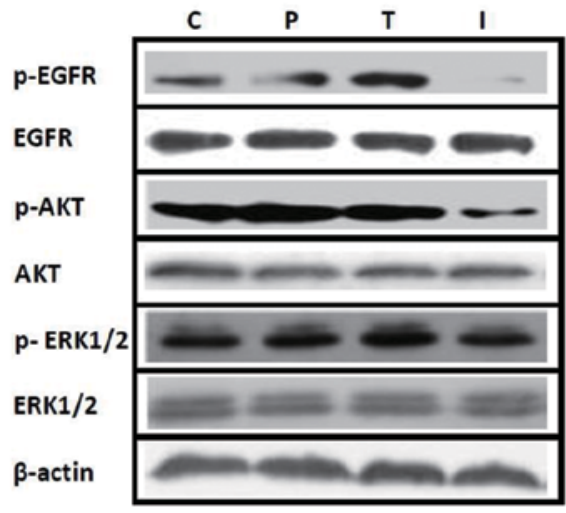

C

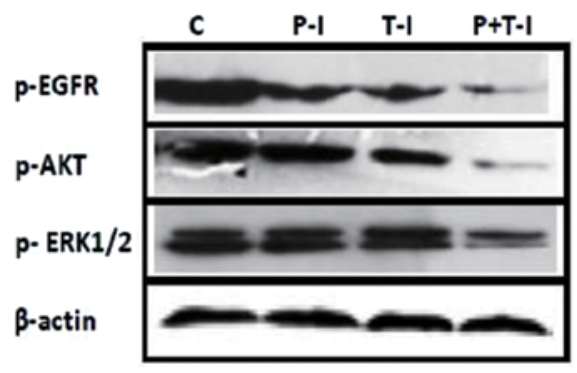

H1975

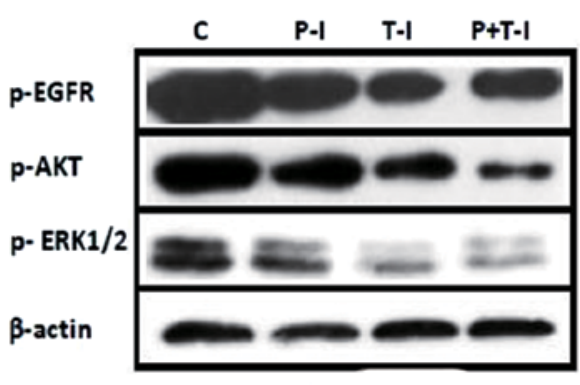

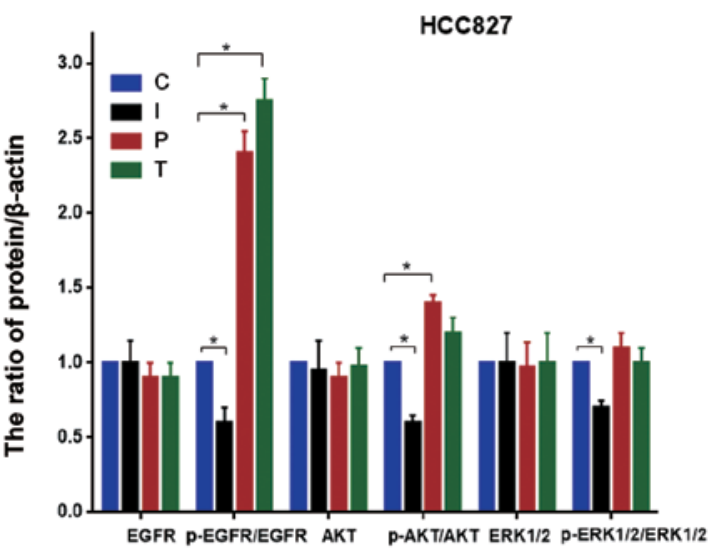
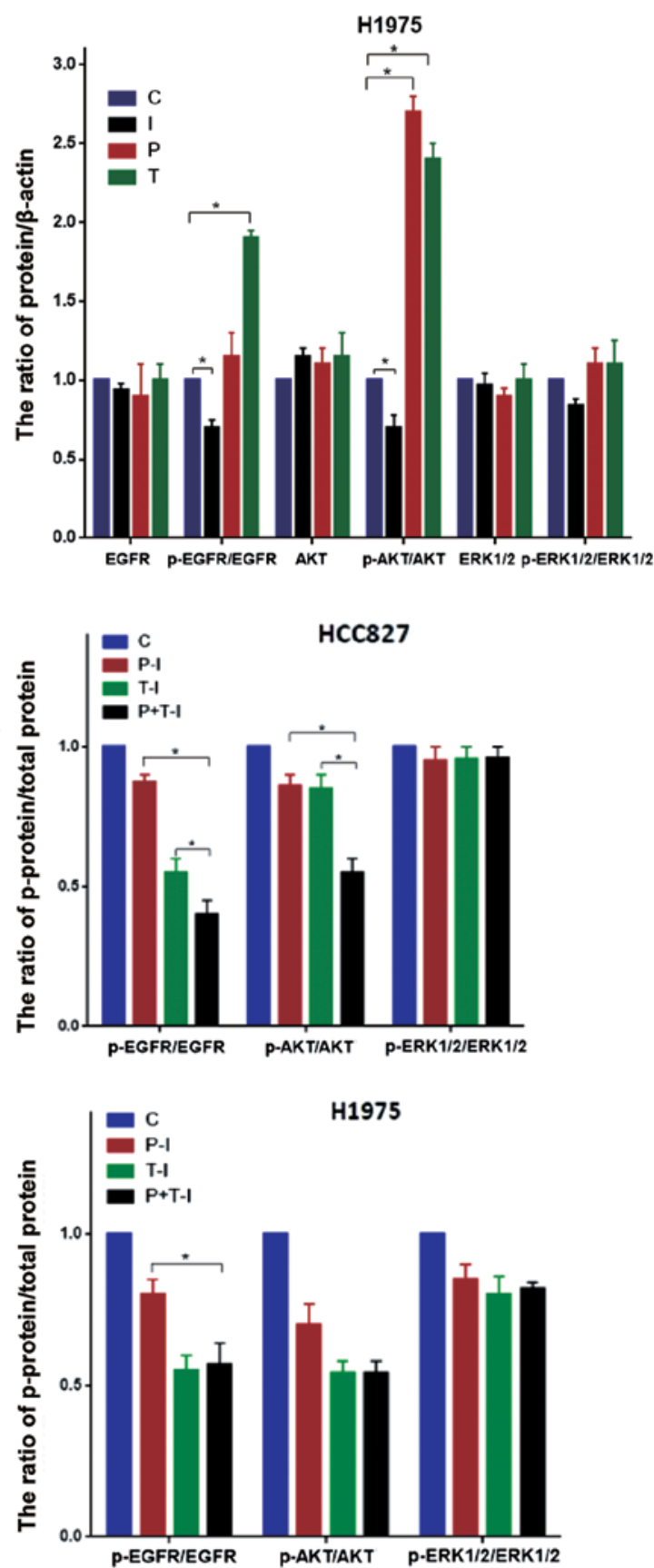

Figure 7. Effects of cisplatin, paclitaxel and icotinib alone or in combination on EGFR and downstream signaling molecular expression in the HCC827 and H1975 cell lines. (A) The HCC827 cell line was treated with cisplatin, paclitaxel and icotinib alone. (B) The H1975 cell line was treated with cisplatin, paclitaxel and icotinib alone. (C) The effect of cisplatin/paclitaxel followed by icotinib on EGFR and downstream signaling molecular expression in the HCC827 and $\mathrm{H} 1975$ cell lines. The HCC827 and H1975 cell lines were treated with $\mathrm{IC}_{50}$ value of drugs. The blots are from one typical experiment. Data are presented as the means \pm SD from three independent experiments. Statistically significant differences are presented as ${ }^{*} \mathrm{p}<0.05$. EGFR, epidermal growth factor receptor. 
the NSCLC cell lines $(28,29)$. Tsai et al determined that the concomitant gefitinib/cisplatin combination shows antagonism in the majority of sensitizing mutations of EGFR wild-type or NSCLC cells, and the three-drug combination is not better than the two-drug combination (30). The present study was innovative since we determined that cisplatin plus paclitaxel followed by icotinib was superior to cisplatin or paclitaxel followed by icotinib in some of the NSCLC cell lines. In addition, the EGFR signaling pathway may have a function in the sequence-dependent interaction in the NSCLC cell lines.

Given that the INTACT-1, INTACT-2, TALENT and TRIBUTE clinical trials were unsuccessful, Gandara et al $(21,31)$ suggested two hypotheses that likely explain these negative results. Firstly, patients were not selected based on a predictive response marker. Secondly, the potentiation of the antagonistic interaction between concurrent EGFR-TKI and chemotherapy may have had a function. Davies et al (20) suggested that EGFR-TKIs primarily cause cell cycle arrest and accumulation of cells in G1, and can interfere with cell cycle-specific cytotoxicity when administered concurrently with chemotherapy. Other studies also showed that pretreatment with EGFR-TKIs causes G1 arrest and effectively abrogates the activity of chemotherapy, resulting in decreased cytotoxicity and apoptosis (32-34). Paclitaxel is an M-phase-specific drug, and these studies may explain the reason of the sequence of paclitaxel followed by icotinib being better than other sequences. Cisplatin is a cell cycle non-specific drug, and the sequence of icotinib followed by cisplatin also caused antagonism. The negative interaction between cisplatin and icotinib may be associated with various cisplatin resistance mechanisms (35-38). Firstly, icotinib may act to decrease cisplatin uptake and/or increase efflux. Secondly, icotinib may change the susceptibility to DNA damage from cisplatin. Anti-apoptosis may also be induced, changing the efficacy of cisplatin.

The present study determined that cisplatin plus paclitaxel followed by icotinib caused more antiproliferative effects, apoptosis and G1 arrest than cisplatin or paclitaxel followed by icotinib in the HCC827 cell line, although not in the H1975 cell line. Improper activation of EGFR results in increased malignant cell survival, proliferation, invasion and metastasis $(39,40)$. The present study and several studies have determined that paclitaxel can increase the expression of EGFR phosphorylation and activate the EGFR signaling pathway $(28,29,41)$. We also determined that cisplatin significantly increased the expression of EGFR phosphorylation in the HCC827 cell line, but not that in the H1975 cell line. However, the exact mechanisms underlying the increased EGFR phosphorylation level remain unknown. In the HCC827 cell line, cisplatin and paclitaxel increased the expression of EGFR phosphorylation, and icotinib decreased the expression of EGFR phosphorylation. This significant increase in EGFR phosphorylation was inhibited by subsequent exposure to icotinib, which may explain the reason for the effect of cisplatin plus paclitaxel followed by icotinib being better than that of cisplatin or paclitaxel followed by icotinib in the HCC827 cell line, but not in the H1975 cell line. The present study has shown that cisplatin/paclitaxel followed by icotinib influenced the expression of p-EGFR and p-AKT, although the expression of p-ERK1/2 was unchanged. Whether the antiproliferative effect of EGFR-TKI and chemotherapy is related to the PI3K/AKT pathway remains to be determined.

In conclusion, the present study has demonstrated that the most advantageous schedule to treat NSCLC in vitro was the sequence of cisplatin/paclitaxel followed by icotinib. We also characterized the molecular mechanisms involved in the synergistic effect between cisplatin/paclitaxel and icotinib against the NSCLC cell lines. Although the extrapolation of in vitro data to the clinical setting should be considered with caution, these results may provide a rationale for the ongoing clinical investigation of the sequential treatment of NSCLC.

\section{Acknowledgements}

The present study was supported by grants from the National Natural Science Foundation of China (no. 81101777), and the social development research project of Shaanxi Provincial Department of Science and Technology (no. 2013K12-08-3).

\section{References}

1. Jemal A, Thun MJ, Ries LA, et al: Annual report to the nation on the status of cancer, 1975-2005, featuring trends in lung cancer, tobacco use, and tobacco control. J Natl Cancer Inst 100: 1672-1694, 2008.

2. Reungwetwattana T, Weroha SJ and Molina JR: Oncogenic pathways, molecularly targeted therapies, and highlighted clinical trials in non-small-cell lung cancer (NSCLC). Clin Lung Cancer 13: 252-266, 2012

3. Salama JK and Vokes EE: New radiotherapy and chemoradiotherapy approaches for non-small-cell lung cancer. J Clin Oncol 31: 1029-1038, 2013.

4. $\mathrm{Xu} \mathrm{Y,Zhang} \mathrm{Y}$ and Ma S: EGFR inhibitors with concurrent thoracic radiation therapy for locally advanced non-small cell lung cancer. Lung Cancer 73: 249-255, 2011.

5. Schiller JH, Harrington D, Belani CP, et al: Comparison of four chemotherapy regimens for advanced non-small-cell lung cancer. New Engl J Med 346: 92-98, 2002.

6. Smit EF, van Meerbeeck JP, Lianes P, et al: Three-arm randomized study of two cisplatin-based regimens and paclitaxel plus gemcitabine in advanced non-small-cell lung cancer: a phase III trial of the European Organization for Research and Treatment of Cancer Lung Cancer Group - EORTC 08975. J Clin Oncol 21: 3909-3917, 2003.

7. Lynch TJ, Bell DW, Sordella R, et al: Activating mutations in the epidermal growth factor receptor underlying responsiveness of non-small-cell lung cancer to gefitinib. New Engl J Med 350: 2129-2139, 2004.

8. Paez JG, Jänne PA, Lee JC, et al: EGFR mutations in lung cancer: correlation with clinical response to gefitinib therapy. Science 304: 1497-1500, 2004.

9. Pao W, Miller V,Zakowski M, et al: EGF receptor gene mutations are common in lung cancers from 'never smokers' and are associated with sensitivity of tumors to gefitinib and erlotinib. Proc Natl Acad Sci USA 101: 13306-13311, 2004.

10. Brandao GD, Brega EF and Spatz A: The role of molecular pathology in non-small-cell lung carcinoma-now and in the future. Curr Oncol 19 (Suppl 1): S24-S32, 2012.

11. Mitsudomi T and Yatabe Y: Epidermal growth factor receptor in relation to tumor development: EGFR gene and cancer. FEBS J 277: 301-308, 2010.

12. Mok TS, Wu YL, Thongprasert S, et al: Gefitinib or carboplatin-paclitaxel in pulmonary adenocarcinoma. New Engl J Med 361: 947-957, 2009.

13. Mitsudomi T, Morita S, Yatabe Y, et al: Gefitinib versus cisplatin plus docetaxel in patients with non-small-cell lung cancer harbouring mutations of the epidermal growth factor receptor (WJTOG3405): an open label, randomised phase 3 trial. Lancet Oncol 11: 121-128, 2010.

14. Maemondo M, Inoue A, Kobayashi K, et al: Gefitinib or chemotherapy for non-small-cell lung cancer with mutated EGFR. New Engl J Med 362: 2380-2388, 2010. 
15. Shepherd FA, Rodrigues Pereira J, Ciuleanu T, et al: Erlotinib in previously treated non-small-cell lung cancer. New Engl J Med 353: 123-132, 2005.

16. Mok TS, Wu YL, Yu CJ, et al: Randomized, placebo-controlled, phase II study of sequential erlotinib and chemotherapy as first-line treatment for advanced non-small-cell lung cancer. J Clin Oncol 27: 5080-5087, 2009.

17. Giaccone G, Herbst RS, Manegold C, et al: Gefitinib in combination with gemcitabine and cisplatin in advanced non-small-cell lung cancer: a phase III trial - INTACT 1. J Clin Oncol 22: 777-784, 2004.

18. Herbst RS, Giaccone G, Schiller JH, et al: Gefitinib in combination with paclitaxel and carboplatin in advanced non-small-cell lung cancer: a phase III trial - INTACT 2. J Clin Oncol 22: 785-794, 2004

19. Herbst RS, Prager D, Hermann R, et al: TRIBUTE: a phase III trial of erlotinib hydrochloride (OSI-774) combined with carboplatin and paclitaxel chemotherapy in advanced non-small-cell lung cancer. J Clin Oncol 23: 5892-5899, 2005.

20. Davies AM, Ho C, Lara PN Jr, Mack P, Gumerlock PH and Gandara DR: Pharmacodynamic separation of epidermal growth factor receptor tyrosine kinase inhibitors and chemotherapy in non-small-cell lung cancer. Clin Lung Cancer 7 : 385-388, 2006.

21. Gandara DR and Gumerlock PH: Epidermal growth factor receptor tyrosine kinase inhibitors plus chemotherapy: case closed or is the jury still out? J Clin Oncol 23: 5856-5858, 2005.

22. Normanno N: Gefitinib and cisplatin-based chemotherapy in non-small-cell lung cancer: simply a bad combination? J Clin Oncol 23: 928-930, 2005.

23. Baselga J: Combining the anti-EGFR agent gefitinib with chemotherapy in non-small-cell lung cancer: how do we go from INTACT to impact? J Clin Oncol 22: 759-761, 2004.

24. Milano G, Spano JP and Leyland-Jones B: EGFR-targeting drugs in combination with cytotoxic agents: from bench to bedside, a contrasted reality. Br J Cancer 99: 1-5, 2008

25. Zhao Q, Shentu J, Xu N, et al: Phase I study of icotinib hydrochloride (BPI-2009H), an oral EGFR tyrosine kinase inhibitor, in patients with advanced NSCLC and other solid tumors. Lung Cancer 73: 195-202, 2011.

26. Shi Y, Zhang L, Liu X, et al: Icotinib versus gefitinib in previously treated advanced non-small-cell lung cancer (ICOGEN): a randomised, double-blind phase 3 non-inferiority trial. Lancet Oncol 14: 953-961, 2013.

27. Xu JM, Azzariti A, Colucci G and Paradiso A: The effect of gefitinib (Iressa, ZD1839) in combination with oxaliplatin is schedule-dependent in colon cancer cell lines. Cancer Chemother Pharmacol 52: 442-448, 2003.
28. Cheng H, An SJ, Dong S, et al: Molecular mechanism of the schedule-dependent synergistic interaction in EGFR-mutant non-small cell lung cancer cell lines treated with paclitaxel and gefitinib. J Hematol Oncol 4: 5, 2011.

29. Cheng H, An SJ, Zhang XC, et al: In vitro sequence-dependent synergism between paclitaxel and gefitinib in human lung cancer cell lines. Cancer Chemother Pharmacol 67: 637-646, 2011.

30. Tsai CM, Chen JT, Stewart DJ, et al: Antagonism between gefitinib and cisplatin in non-small cell lung cancer cells: why randomized trials failed? J Thorac Oncol 6: 559-568, 2011.

31. Gandara D, Narayan S, Lara PN Jr, et al: Integration of novel therapeutics into combined modality therapy of locally advanced non-small cell lung cancer. Clin Cancer Res 11: 5057s-5062s, 2005.

32. Li T, Ling YH, Goldman ID and Perez-Soler R: Scheduledependent cytotoxic synergism of pemetrexed and erlotinib in human non-small cell lung cancer cells. Clin Cancer Res 13: 3413-3422, 2007.

33. Gumerlock PH, Pryde BJ, Kimura T, et al: Enhanced cytotoxicity of docetaxel OSI-774 combination in non-small cell lung carcinoma (NSCLC). J Clin Oncol 22: 2661, 2003.

34. Mahaffey CM, Davies AM, Lara PN Jr, et al: Schedule-dependent apoptosis in K-ras mutant non-small-cell lung cancer cell lines treated with docetaxel and erlotinib: rationale for pharmacodynamic separation. Clin Lung Cancer 8: 548-553, 2007.

35. Stewart DJ, Raaphorst GP, Yau J and Beaubien AR: Active vs. passive resistance, dose-response relationships, high dose chemotherapy, and resistance modulation: a hypothesis. Invest New Drugs 14: 115-130, 1996.

36. Stewart DJ: Mechanisms of resistance to cisplatin and carboplatin. Crit Rev Oncol Hematol 63: 12-31, 2007.

37. Hall MD, Okabe M, Shen DW, Liang XJ and Gottesman MM: The role of cellular accumulation in determining sensitivity to platinum-based chemotherapy. Annu Rev Pharmacol Toxicol 48: 495-535, 2008

38. Stewart DJ: Tumor and host factors that may limit efficacy of chemotherapy in non-small cell and small cell lung cancer. Crit Rev Oncol Hematol 75: 173-234, 2010.

39. Citri A and Yarden Y: EGF-ERBB signalling: towards the systems level. Nat Rev Mol Cell Biol 7: 505-516, 2006.

40. Ciardiello $\mathrm{F}$ and Tortora G: EGFR antagonists in cancer treatment. New Engl J Med 358: 1160-1174, 2008.

41. Van Schaeybroeck S, Kyula J, Kelly DM, et al: Chemotherapyinduced epidermal growth factor receptor activation determines response to combined gefitinib/chemotherapy treatment in non-small cell lung cancer cells. Mol Cancer Ther 5: 1154-1165, 2006. 